\title{
Effect of Differential Reinforcements on Reducing Problematic Behaviours among Children with Intellectual Disability in the Classrooms
}

\author{
Mr. Shashi $\operatorname{Kumar}^{1}{ }^{*}$, Dr Chavan. B. S. ${ }^{2}$, Ms. Vani Ratnam ${ }^{3}$
}

\section{ABSTRACT}

A structured behaviour modification programme relatively improves the various skill behaviours among children with intellectual disabilities as well as decreases the problematic behaviours, when it is used in a systematic way in school classrooms. Present study represents the effect of systematic representation of differential reinforcements to decrease the problematic behaviours among the children with intellectual disabilities. The main objective of the present study was to study the effect of differential reinforcements in decreasing problematic behaviours among children with intellectual disability. This study was conducted on the sample of twenty students, selected from the Regional Institute for Mentally Handicapped Chandigarh, with informed consent of parents with pre selected inclusion and exclusion criteria and randomly assigned to the two groups. Experimental group was treated by the experimenter with intervention package after pre test up to 60 sessions and control group was remained untreated. After the treatment and analysis, experimenter found that students of experimental group who treated with the treatment package have significant decrease in problematic behaviours with t value 8.450, in comparison to control group.

Keywords: Differential Reinforcements, Reducing Problematic Behaviours, Children, Intellectual Disability, Classrooms.

In classroom situations, there are many behaviors that a school psychologist or teacher may wish to increase. For example, he or she may wish to increase reading and math fluency. In managing the classroom, he or she may wish to increase appropriate responding and on task behaviors. In order to increase targeted behaviors, effective rein forcers commonly need to be identified. (Ivancic, 2000; Sulzer-Azaroff \& Mayer, 1986). There is a great deal of literature supporting the

\footnotetext{
${ }^{1}$ Special Educator RIMH

2 Joint Director RIMH

${ }^{3}$ Officer In Charge RIMH

*Responding Author

(C) 2016 I S Kumar, B Chavan, V Ratnam; licensee IJIP. This is an Open Access Research distributed under the terms of the Creative Commons Attribution License (http://creativecommons.org/licenses/by/2.0), which permits unrestricted use, distribution, and reproduction in any Medium, provided the original work is properly cited.
} 


\section{Effect of Differential Reinforcements on Reducing Problematic Behaviours among Children with Intellectual Disability in the Classrooms}

effect of positive reinforcement on increasing academic skills. It has been demonstrated that contingent reward and instruction both work to increase the number of words correctly read per minute (Noell, Freeland, Witt, \& Gansle, 2001; Noell et al., 1998). Rewards in the form of praise and tokens have been shown to be an important part of some effective interventions such as classwide peer tutoring (Delquadri, Greenwood, Whorton, Carta, \& Hall, 1986; Greenwood, Arreaga-Mayer, Utley,Gavin, \& Terry, 2001). Home-based reinforcement of school behavior has been effectively used to increase a variety of appropriate behaviors and decrease a host of inappropriate behaviors (Atkeson \& Forehand, 1979; Barth, 1979). In addition, a review of the differential reinforcement literature supports the effectiveness of these reinforcement procedures when used in classrooms (Sulzer-Azaroff \& Mayer, 1986).

The study "Reducing self-stimulatory stereotyped body rocking of a retarded boy by differential reinforcement technique and environmental manipulation" by Nanda. B. (1999) examined the effectiveness of differential reinforcement of lower rates of human techniques (DRA) and environment manipulation on 4 years old retarded child's self- stimulatory stereotyped bodyrocking behavior. The results indicated that the above mentioned techniques were effective as the frequency of rocking behavior reduced from 35 to 5 at the end of the treatment.

The use of differential reinforcement is recommended in early intervention (EI) programs because children in EI often do not acquire skills in the absence of motivational procedures (Karsten \& Carr, 2009; Leaf \& McEachin, 1999; Lovaas, 2003). In addition, prompting procedures may be necessary initially, because children who require EI may not have extensive skill repertoires that could be exposed to differential reinforcement.

A study conducted by Ringdahl et al. (2002), utilized a differential-reinforcement-based treatment package for the reduction of problem behaviors during an instructional setting with an 8-year old girl diagnosed with autism functioning in the moderate range of mental retardation. Researchers found DRA without instructional fading resulted in an initial increase in problem behavior, but it decreased across sessions.

Several variables may influence the effectiveness of differential reinforcement. For example, baseline levels of responding may provide information regarding whether to apply differential reinforcement for independent responding from the onset of treatment or fade reinforcement for prompted responses over time. If the participant engages in some level of correct responding during baseline, differential reinforcement could be implemented for independent responses immediately during learning trials. However, if the participant displays no correct responding during baseline, the therapist could fade reinforcement for prompted responses once the child engages in some level of correct independent responding. Applying differential reinforcement too early in treatment may prematurely extinguish correct prompted responding. Only one of the studies we reviewed included a baseline. Thus, it is difficult to determine whether the 


\section{Effect of Differential Reinforcements on Reducing Problematic Behaviours among Children with Intellectual Disability in the Classrooms}

effectiveness of differential reinforcement (or lack thereof) may be explained by baseline responding; this is an important topic of future research.

An additional variable that may influence the effectiveness of differential reinforcement is prior exposure to non differential reinforcement. Hausman, Kahng, and Ingvarsson (in press) and Olenick and Pear (1980)incorporated a phase of no differential reinforcement prior to evaluating differential reinforcement with the same target stimuli. It remains unclear whether the extended exposure to nondifferential reinforcement slowed acquisition of the target skills in these evaluations. Errorless learning (e.g., prompt delay), in which no differential reinforcement is provided prior to differential reinforcement (e.g., in one or two sessions of a 0-s prompt delay), is the most common prompting procedure used in EI programs (Love, Carr, Almason, \& Petursdottir, 2009). Therefore, EI programs may use no differential reinforcement in the initial portion of treatment but to a lesser extent than the aforementioned studies. Additional research evaluating differential reinforcement under conditions more closely approximating procedures used in EI programs is needed to determine the extent to which the results would be similar to those in the studies we reviewed.

Future studies are needed to address gaps in the literature regarding best practices for the use of differential reinforcement. Until additional research on differential reinforcement is conducted, clinicians may struggle to identify how best to incorporate differential reinforcement into acquisition-based programs in clinical practice.

\section{METHOD}

Present study is a cross sectional experimental study, intended to see the effect of structured behaviour modification programme on reducing problematic behaviours. Study was aimed to see the effect of structured behaviour modification program by using differential reinforcements on reducing problem behaviours among children with intellectual Disability. In the present study it is hypothesized that there is no significant effect of Differential Reinforcements on reducing problem behaviours among children with ID.

To conduct the present study participants were selected from the Regional Institute for mentally handicapped (RIMH) with the informed consent of administrator and parents. In the present study researcher had selected the 60 students from the RIMH with pre determined inclusion and exclusion criteria, purposively and observe them for as participant observer for 15 days regularly. In the result of observation researcher found the 49 students having severe behaviour problems. Researcher had made a list of these students and created a random table through statistical package for the selection of the samples for the present study. Out these 49 students 20 students had been selected for the present study and randomly assigned to two different groups, as experimental group and control group. In the sampling process researcher had selected the students who are diagnosed as intellectually disabled under the ICD 10, DCR criteria having IQ 


\section{Effect of Differential Reinforcements on Reducing Problematic Behaviours among Children with Intellectual Disability in the Classrooms}

range- 35 to 49 between the ages of 15 to 18 years with both genders. Although co morbid conditions of intellectual disability and non consenting students excluded from the study.

\section{Instrument and material}

In the present study researcher had used the Behavioural Assessment Scale for Indian Children (BASIC -MR) Part - B as tool for data collection. This tool is developed by Dr. R. Peshawaria and S. Venkateshan et' all in 1992. It is a tool validated in Indian context and reliable to assess the needs of students with intellectual disability. This tool has two parts, A and B. Part A deals with the skill behavioural assessment and Part B deals with the Problem Behavioural assessment. In this tool there are 75 items under different domains to measure the problem behaviours of students with intellectual disability. Scoring pattern is $0,1,2$ to rate the behaviour. This tool can be used by the special educators, parents and care takers by using direct observation of the child or by interviewing the teachers or parents who are directly linked with student.

In the present study researcher had developed an individualized structured behaviour modification package (SBMP) to give intervention to the samples of experimental group. In this package researcher had defined the reward preferences of the samples at initial stage and determined the priority level of samples for reward. In the package researcher also defined token rewards to teach the students differentiation between the skill behaviours and problem behaviours. In this package researcher had counsel the parents, care takers and teachers to follow the instructions of researcher strictly.

To conduct the present study researcher had assessed to both the groups on BASIC(-MR) Part B to find the behaviours with high frequency of occurrence through observation and interview of parents and teachers. Researcher had selected the behaviours having 2 scoring on the tool and total scores had been taken as the pre test scores excluding score , 0 and 1 . Then researcher had selected the five common problem behaviours for each sample and ABC analysis was done to find the causes of the problem behaviours. Researcher had developed an individualized SBMP (Differential Reinforcements) for each child according to their ABC analysis. This package was implemented during the routine class room activities up to 60 sessions regularly, five days weekly. After the 60 sessions researcher had done the re - observation of samples for change in targeted behaviours. 


\section{RESULTS AND DISCUSSION}

Table 1: Comparisons of Pre and Post-test mean Scores on BASIC-MR Part B of the Subjects who received intervention (Experimental Group) - Results of Paired T-Test:

\begin{tabular}{|l|l|l|l|l|l|}
\hline \multicolumn{2}{|l|}{ Domain } & N & Mean & $\begin{array}{l}\text { Std. } \\
\text { Deviation }\end{array}$ & $\begin{array}{l}\text { t-value, df \& p- } \\
\text { value }\end{array}$ \\
\cline { 1 - 5 } $\begin{array}{l}\text { Experimental } \\
\text { Group }\end{array}$ & Pre test & 10 & 13.20 & 1.54 & $\begin{array}{l}\mathrm{t}^{\prime}=11.857, \quad \mathrm{df}=9, \\
\mathrm{p}<0.01\end{array}$ \\
\cline { 2 - 6 } & Post test & 10 & 4.20 & 1.52 & \\
\hline
\end{tabular}

Table 1: indicate the pre test post test mean scores of the experimental group. It is clear from the above table that pre test mean scores is 13.20 and standard deviation is 1.54 and post test mean scores is 4.20 and standard deviation is 1.52 . Difference between pre test and post test mean score is 9.00, which indicates that there is a decrease in problem behaviours among students with ID in classroom. However to see whether there is any significant difference in the mean scores Paired - sample t test was conducted.

In the above table calculated value of $t$ is 11.857, whereas table value is 3.25 at $1 \%$ level of significance $(\mathrm{P}<0.01)$. Hence null hypothesis is rejected at 0.01 level. So it is concluded that SBMP significantly decrease the problem behaviours among students with ID in classroom settings.

Table 2: Comparisons of Post-test mean Scores on BASIC-MR Part B of the Subjects of both the Groups. (Between the Groups) - Results of Paired T-Test:

\begin{tabular}{|l|l|l|l|l|l|}
\hline \multicolumn{2}{|l|}{ Domain } & N & Mean & $\begin{array}{l}\text { Std. } \\
\text { Deviation }\end{array}$ & $\begin{array}{l}\text { t-value, df \& p- } \\
\text { value }\end{array}$ \\
\hline $\begin{array}{l}\text { Between the } \\
\text { Groups }\end{array}$ & Pre test & 10 & 9.30 & 1.41 & $\begin{array}{l}\text { t'=8.450, df }=9, \\
\text { p }<0.01\end{array}$ \\
\cline { 2 - 6 } & Post test & 10 & 4.90 & 1.52 & \\
\hline
\end{tabular}

Table2: indicate the post test mean scores of the experimental group and control group. It is clear from the above table that pre test mean scores is 9.30 and standard deviation is 1.41 and post test mean scores is 4.90 and standard deviation is 1.52. Difference between pre test and post test mean score is 4.40 , which indicates that there is a difference in problem behaviours among students with ID in classroom of both the groups. It also indicate that calculated value of $t$ is 8.450 , whereas table value is 3.25 at $1 \%$ level of significance $(\mathrm{P}<0.01)$. Hence null hypothesis is rejected at 0.01 level. So it is concluded that there is a significant difference in the score of problem behaviours among both the groups.

This study had examined the appropriateness of the SBMP (Differential Reinforcements) in decreasing the problem behaviours among students with ID in classrooms. In relation to the PB of students with ID, our study provides insight for how to decrease the PB. Although 


\section{Effect of Differential Reinforcements on Reducing Problematic Behaviours among Children with Intellectual Disability in the Classrooms}

effectiveness of the SBMP (Differential Reinforcements) depends on the prior exposure to the non differential reinforcements (Hausman, Kahng, and Ingvarsson (in press) and Olenick and Pear 1980), but it improve the skill behaviours and decrease the problem behaviours.

Similar to previous studies (Ringdahl et al. 2002), this study also supports that SBMP (Differential Reinforcements) very helpful in decrease the problem behaviours among students with intellectual disabilities in the classroom setting.

\section{STUDY LIMITATION}

Present study is a study on small samples with some specific limitations. In the present study pre test is based on the observation of students and interview of the care takers, parents and teachers, hence the reliability of data may effected by the biases. Although there health issues of samples, absence of samples from intervention and following the routines and instructions of the researcher by care takers, parents and teachers may intervene the overall Impact of intervention.

\section{CONCLUSION}

Despite of the above limitations this study has important practical implications in classroom settings to reduce the problematic behaviours among students with intellectual disability. Practically, the findings of the study may help the professionals to develop the SBMP for students with intellectual disability and to use the differential reinforcements in reducing problem behaviours among students with intellectual disability. Further, more research is needed to better understand the variable degree and depth of familiarity.

\section{REFERENCES}

Atkeson, B. M., \& Forehand, R. (1979). Home-based reinforcement programs designed to modify classroom behavior: A review and methodological evaluation. Psychological Bulletin, 86(6), 1298-1308

Austin \& J. E. Carr (Eds.), Handbook of applied behavior analysis (pp.19-38), Reno, NV; Context Press.

Delquadri, J., Greenwood, C.R., Whorton, D., Carta, J. J., \& Hall, R. V. (1986). Classwide peer tutoring. Exceptional Children, 52(6), 535-542.

Greenwood, C. R., Arreaga-Mayer, C., Utley, C. A., Gavin, K. M., \& Terry, B. J. (2001). Classwide peer tutoring learning management system: Applications with elementary level English language learners. Remedial and Special Education, 22(1), 34-47.

Hausman N.L, Kahng S, Ingvarsson E.T. A comparison of reinforcement schedules to increase independent responding in individuals with autism. Journal of Applied Behavior Analysis. in press.[PubMed]

Ivancic, M. T. (2000). Stimulus preference and reinforcer assessment applications. In J.

Karsten A.M, Carr J.E. The effects of differential reinforcement of unprompted responding on the skill acquisition of children with autism. Journal of Applied Behavior Analysis. 2009;42:327-334.[PMC free article] [PubMed] 


\section{Effect of Differential Reinforcements on Reducing Problematic Behaviours among Children with Intellectual Disability in the Classrooms}

Leaf R, McEachin J. A work in progress: Behavior management strategies and a curriculum for intensive behavioral treatment of autism. New York: DRL Books; 1999.

Lovaas O.I. Teaching individuals with developmental delays: Basic intervention techniques. Austin, TX: Pro-Ed; 2003.

Love J.R, Carr J.E, Almason S.M, Petursdottir A.I. Early and intensive behavioral intervention for autism: A survey of clinical practices. Research in Autism Spectrum Disorders. 2009;3:421-428.

Nanda, B.(1999) Reducing self-stimulatory stereotyped body rocking of a retarded boy by differential reinforcement technique and environmental manipulation. Indian Journal of Clinical Psychology, 26, 209-214.

Noell, G. H., Freeland, J. T., Witt, J. C., \& Gansle, K. A. (2001). Using brief assessments to identify effective interventions for individual students, Journal of School Psychology, 39(4), 335-355.

Noell, G. H., Gansle, K. A., Witt, J. C., Whitmarsh, E. L., Freeland, J. T., LaFleur, L. H., Gilbertson, D. N., \& Northup, J. (1998). Effects of contingent reward and instruction on oral reading performance at differing levels of passage difficulty. Journal of Applied Behavior Analysis, 31(4), 659-663.

Olenick D.L, Pear J.J. Differential reinforcement of correct responses to probes and prompts in picture-name training with severely retarded children. Journal of Applied Behavior Analysis. 1980;13:77-89.[PMC free article] [PubMed]

Sulzer-Azaroff, B., \& Mayer, R. G. (1986). Achieving education excellence: Using behavioral strategies. New York: Holt, Rinehart, \& Winston. 